\title{
Alleviation of ‘Generation Gap’ Through Socio-Economic Issues Involvement
}

\author{
Mohamed Buheji \\ Correspondence: International Inspiration Economy Project, Bahrain. E-mail: buhejim@gmail.com
}

Received: August 7, 2019 Accepted: August 29, 2019 Online Published: September 15, 2019

doi:10.5539/res.v11n4p12 URL: https://doi.org/10.5539/res.v11n4p12

\begin{abstract}
The generation gap has been an issue that is rising in many communities. This paper investigates the challenges of 'generation gap' and propose a model for closing it. The synthesis of the literature review defines the types of generation gaps and the factors that increase this gap. The contemporary practices and measures used to close this intergeneration gap are identified. Two main approaches are retrieved as a reflection from the literature reviewed: mindset approach and socio-economic engagement approach.

The researcher presents a case study that proposes a theoretical framework about connecting the different generations and engaging them through solving socio-economic issues of common interest. The paper recommends further studies in this line where different generations would be engaged more to share knowledge and values and mitigate risks of further gap widening, while solving their socio-economic problems.
\end{abstract}

Keywords: generation gap, intergeneration gap, youth economy, socio-economic issues, alleviation of the generation gap, socio-economic engagement, youth mindset

\section{Introduction}

Generations difference have been noted by Furlong (2016), where he emphasised that this generation difference become more apparent when youth transits into adulthood. As per Furlong some of this gap is natural and others are done by deliberate one and can be seen clearly in gathering as in the market, the clubs, the coffee shops and the activity centre.

The sociological theory of a generation gap first came to light in the 1960s, when the younger generation, now known as the baby boomers, shown to have a large gap with their parents' values and views in life, Govitvatana (2001). Since then, many studies have shown that physical isolation usually combines the mental isolation between the generations, i.e. usually you would find little interaction or even barriers of interaction across the ages. This isolation used to be clear if the differences in ages of about one decade or more, but today, even if the age difference is less than three years, we would notice this physical isolation. Actually, now the barriers are becoming so difficult that rarely you would see that this chain could be broken.

Synthesis of the generational gap literature review shows there are different types of perceptions about the extent of the gap. One type of research sees that the gap between the generations is too deep. Other, type of research sees that there is no big gap between the generations today and what is experienced is only part of the norms of any other cycle of generation. The other literature shows there are selective gaps between the generations. Hence, we can see there is research that is pessimistic about the generational gap, and other research that is optimistic about the generational gap. Certain studies show that generational gap is the cause of identity crisis and the faded role of the common ties that were influenced by the religion, or the school, or the community. Buheji (2018b), Mannheim (1952).

\section{Literature Review}

\subsection{Definitions of Generation Gap}

A generation is defined as the people who are born in the same historical period and those who live in the same socio-historical atmosphere and have similar youth experiences during their formation years.

A generation gap is the difference of mindset between one generation and the other, which influence their assumptions, perceptions, paradigms, attitudes, behaviours and reflections. Such gap influence also their beliefs and values. In today's usage, generation gap often refers to a perceived gap between younger people and their parents, or grandparents. Govitvatana (2001). 
Generation makes a unity or distinction between the people who have characteristic viewpoints based on shared experiences (Mannheim, 1952). Wilhelm Dilthey (1923) emphasised the importance of the experiences which are conventionally categorised as conceptual and mental factors along with their influence on the youth and formation years and where the conceptualisation about generation does not merely refer to the statistically born generation.

According to the Oxford English Dictionary, the generational gap is about the failure or inability of young and old generations in mutual understanding. Thus, if we want to close this intergeneration gap, we need to establish a mutual interest between the two generations. Hence, the intergeneration gap occurs when a lack of transmission of values occurs between the previous generation to the next one. This type of mismatch of values between the generations comes due to the different experiences built between the two parties.

Generational disconnection inside families means that youth would usually change their reference group, other than their parents. This creates a type of defect in the relationships between the different generation in one household. Socio-economically, the generation gap refers to the differences that emerge during economic or social or political differentiation or due to the influence of sudden modern lifestyle. Buheji (2018d), Woodman and Wyn (2015).

\subsection{Importance of Closing Generation Gap}

Bridging the generation gap between parent and children is essential for any community long term family stability. Frey (2018) sees that the generational gap is like a "diversity explosion". Experts believe that the phenomenon of the generational gap has not been a very serious issue in the past, until the emergence of modern industrial society. Govitvatana (2001).

Before the 20th century, humanity did not experience this level of confrontation between the young and old generations as we are experiencing it in today's world. With the shaking up of the respect based on the social status, or acceptance of the authority of elders out of the term of respect, no more account is taken into the relationship between different age groups. i.e. Participation of youth in adults' life and gatherings, became less and felt not to be related to obligation any more.

Hence, over time, we are experiencing more less transfer of cultural and heritage knowledge assets from one generation to the other. The current interactions among different age groups, and the continuation of similar thoughts and some unity behavioural patterns became much less, as we witness the emergence of new variables that increase the conflicts between the generations and slow cultural modifications efforts.

Generational differences have emerged as a result of the rapid industrialisation and innovation of the way we define societies. With the speed of the course of the modernisation at cultural, social, organisational, and economic levels, youth are possessing more information than the older generation; their ability to attend and react to different fields are much more compared to their parents.

\subsection{Types of Generation Gaps}

In the Handbook of Youth Economy, Buheji (2018) mentioned that the generation gaps found to differ as per the type of generation they belong too. This gap seems to widen much more if the gap is more than five years. Once we are diagnosing the type of generation gaps, we would find that they would be seen in the following areas:

\subsubsection{Language Use}

One of the most challenging generation gaps is the difficulty of communicating through a universal language. Today more complications in relevance to common language communication, be it at home, or work, or at school. Commonly, any new generation seeks to define themselves as something apart from the old. Usually, each generation tries to adopt new lingo and slang, allowing a generation to create a sense of division from the previous one.

Through slang words and phrases, social identity is identified. This slang helps to be part of the group to maintain their popularity among their friends. A form of slang or texting even developed more over the years where children of today are increasingly using personal technological devices that make then differentiate themselves and create social circles apart from their families. The use of mobile phones and instant messaging made children and youth to invent their private written language to feel independence. As time goes on, technology is being introduced to individuals at even younger ages. Buheji (2018b) and Furlong (2016).

Another phenomenon within a language that works to define a generation gap occurs within families in which different generations speak different primary languages

\subsubsection{Technological Use}

Every generation develops its differentiation with the development of new technology that suites its needs. For example, when the e-mail and messenger started with the development of the internet, more gaps developed between youth and their grandparents that could not coop with this type of communication technology. When the Baby Boomers interacted 
with the technology of the Atari games and video recorders, this created a bit gap with their family and their parent. Today Y, Z and Alpha generations teach their parents how to manoeuvre with different technology gadgets starting from mobile phones and social media. This vast technology literacy makes the Baby Boomers feel and appreciates their parents' feelings in the seventies and early eighties. Furlong (2016).

In a study about the use of technology in the different generations of the Baby Boomers (born 1946-1964), the X generation (born 1965-1980), the Y Generation (born 1981-2000) and Z Generation (born 2000 to present). Clearly, there was a generation gap between how they deal with available technology at home, specifically the mobile and internet use. The research, as expected, showed generational gaps between the different forms of technology used. For example, a clear gap is shown between even the $\mathrm{Z}$ and the $\mathrm{Y}$ generations in the way texting and talking on mobile phones. The amount of the utilisation of mobile phones in reading and texting messages even created a difference between these latest generations in relevance to the $\mathrm{X}$ and the Baby Boomers. Govitvatana (2001).

\subsection{Factors that Increase the Generation Gap}

Several factors affect the generations gap; the most reliable and most consistent predictors are sex, age, child's marital status, and residential proximity.

The generations gaps targeted in this literature review are beyond only the general different likes, dislikes and frequency of thought flow that has been existing between the younger and the older generations for a long time. It is beyond the habit of reading books, classical music, walking with friends, or attending a gathering of the family. It is also beyond the preference of social networking or different fashion, or food habits taste. Govitvatana (2001).

\subsubsection{Parents Causing the Generation Gap}

Despite parents, today are getting closer to their children than ever before. Still, the new generation sees their parents' generation old-fashioned. Parents often contribute to the gap between them and their children by pushing their kid's beyond their limits. When parents demand higher than their children limits, or pushes their children beyond the family socio-economic situation, the children go astray from being obedient to resistant to what their fathers say. Buheji (2018d).

When the parents have fussy behaviours with their children, arguments convert into disputes.

\subsubsection{A Lonely Generation}

Research shows that today pressure of work environment found to lead to social isolation. Studies also show that loneliness is not something only older people experience, but is equally likely to affect any age-group. Moreover, what is noticeable is that the study found that loneliness hits a peak for twenty-somethings.

The trend of having more young people work in strange cities while leaving their older people without loved ones. Most younger graduates are keen to build a career and start a family, and in doing so sometimes, they lose track of friends and family and thus with time lose touch in older people.

One of the reasons for the sharp increase in loneliness is that many people and especially youth generations, started to replace real friends with external contacts on social media. This led to the elimination of their social assets to near nil. Nowadays young people are best friends with their parents at 60 years does not seem old any more. More and more parents are enjoying a really warm relationship with their children and grandchildren, and even with their children's friends. Yet there is certainly a "Digital Gap". Furlong (2016) and Buheji (2018b).

\subsubsection{Communication Challenge With Dynamic Workplace}

As many Y, Z and soon Alpha generation are entering the workplace, more intergeneration language, and communication models are needed. Depending on the country, the level of education and the level of expectation from the workplace; the amount of gap would be decided. Govitvatana (2001).

Both generations expect from other generation to behave like them. As the young generation looks for a rapid and adventurous life, the elders would be looking to promote a healthy and well-balanced lifestyle. More attention to generational differences will make any organisation more efficient and effective towards their targeted outcome. Govitvatana (2001).

By realising the need for mitigating the problem of unemployment, the young generation found to neglect their accountability towards their elders. However, as mentioned in Buheji (2019) it is very important that older generation in the workplace do not try to impose their work-related norms onto a generation who are trying to create their own lives and under very different circumstances.

\subsubsection{Intergeneration Gap due to Increase in Life Expectations}

Today, millennials generation differ in their life expectations comparing to their parents. This is a generation expecting support from parents until they find a job. They are evaluating the job terms and the working conditions, besides good pay. 
They are expecting that their organisation keeps up with the rapid technological advancements, appreciate the right of work-life balance, besides being an inspiring place to work.

Most of these inflated expectations have direct results on the generation's performance. Many of these challenges might influence even later in life the attitudes and the commitments towards family life and other priorities in life. This can be expected due most millennials encountered with an educational system which inflated the grades and standardised the tests. Hence, such generation expects more frequent positive feedbacks and a good pay job. Buheji (2019, 2018b, 2018c).

Hence, we can learn that one of the main differentiation between each generation is the level of tolerance. Whether tolerance to challenging work; or tolerance to different attitudes or different background.

Studies have shown that their reliance on technology has made millennials less comfortable with face-to-face interaction and deciphering verbal cues. However, technological proficiency also has its benefits; millennials are far more effective in multitasking, responding to visual stimulation, and filtering information than older generations.

\subsubsection{Intergenerational Consciousness and Mobility}

Generational consciousness is built when a group of people become mindful of the social, economic, or political changes and how it can bring awareness to the shared interests and values. Such mindful conditions make the generation create their own interpretations of the world based on personal encounters which set them apart from other generations. Woodman and Wyn (2015).

The intergenerational mobility focus on the changes in social status, which occurs from the older generation to the children's generation. Lack of attention to generational differences will make any organisation less attractive to youth and increases their mobility. With more intergenerational mobility, higher resource management costs. Buheji (2018b). To encourage bridging the generation gap the organisation need to create a suitable atmosphere that engages people to learn from experimentation and to learn from each other, as there are no 'one size fits all' solution.

\subsubsection{Understanding the Millennials}

Millennials generations are considered all those who are born between 1985-1995 and might have extended in certain countries till early 2000. So, they are the generations that are categorised as Y, Z and even Alpha. They are also called Generation Me since this is a generation that is living self-obsession. These generations played less outdoors and mostly engaged in games consoles. This is the generation that prefers texting, chatting or sending WhatsApp than voice calls.

The majority of youth in Generation Me in the developed and emerging economies would have owned a mobile computer, or a mobile phone and would have accessibility to the internet and instant messaging. They are a generation that use social networking sites, such as Facebook, to create a different sense of belonging to friends, and which rarely would refer to TV for news. Buheji (2018b).

These Millennials' generations found to associate their job satisfaction with free flow of information are also found unique in their volunteering activity, which increases almost three-times than the previous generations.

\subsection{Practices that Close the Intergeneration Gap}

\subsubsection{Intergenerational Living}

In 2012 a report by the USA National Academy of Sciences confirmed that the social isolation and loneliness in older men and women are creating more increased mortality. Intergenerational living is one method being used worldwide as a means of combating such feelings. A nursing home in Deventer, The Netherlands, developed a program wherein students from a local university are provided small, rent-free apartments within the nursing home facility. In exchange, the students volunteer a minimum of 30 hours per month to spend time with the seniors. The students will watch sports with the seniors, celebrate birthdays, and simply keep them company during illnesses and times of distress. Programs similar to the Netherlands' program were developed as far back as the mid-1990s in Barcelona, Spain. In Spain's program, students were placed in seniors' homes, with a similar goal of free or cheap housing in exchange for companionship for the elderly. That program quickly spread to 27 other cities throughout Spain, and similar programs can be found in Lyon, France, and Cleveland, Ohio.

\subsubsection{Effect of Experience on the Level of Generational Gap}

The cultural extension requires cultural transmission that ensure the best communication from one generation to another. To ensure minimum generation gaps, more educational training needs to be delivered during childhood and adolescence.

The generation gap depends on the changed psychology of each child, which is influenced by their age. Realising the risks of generation gap due to the rapidly changing society, the Chinese government established clusters in the communities, like gathering, parks that bring the best of each generation through common interests as cross-teaching and reverse learning spots that offer an arena for sports, healthy practices, traditional medicine, traditional music and cooking classes. 
Also, many leading governments as in Singapore they started to provide human values and ethical education at school and supported by compulsory voluntary visits to elderly. Buheji (2018b).

The experience about priorities in life also found to play a role in generations gaps. Many youths feel they are like being in an endless desert race. However, in reality, life is not like race with non-stop; it is rather about pauses after learning from failure and learning from experiential life exercises. Najafiasl (2015).

\subsubsection{Family-Youth Relationship}

In order to ensure minimum intergeneration gap, the family-youth relation styles need to move from being authoritarian to more of permissive style. The authoritarian family-style creates maybe the youth of whom would look like that they have more indisputable obedience, but could create sudden generation gap once oppression is removed. Hence, such type of family-style should be avoided as they create only bad experiences of rigid opinions from all the generations targeted. Today families need to focus on reinforcing positive behaviours.

A semi-democratic family judge their youth's ideas based on their attitudes and behaviours. While the permissive democratic family is based on high flexibility with few expectations and low training supervision. Supportive and training behaviours of the family with children help to close the 'intergenerational gap' to the minimum. Through the hands-on transmission of values from parents to children, there are more possibilities that children would accept their families' values. The wrong perception of family beliefs and values would lead to disagreement between the different generations.

As youth enter adolescence, the ties of their dependency on the family weaken or take new forms. At this stage, young people want or look for new freedoms, and they are not expecting any significant responsibilities. Hence, at this stage, the quality of the family-youth relationship, i.e. intimacy, is a very important factor in controlling the generation gap. This affects the youth's perception about their family's most important beliefs, and reflect on the degree of the family agreement throughout different generations. This can be seen clearly in the quality of family business who gone through thi $^{\text {rd }}$ and four ${ }^{\text {th }}$ generations, especially in Japan. Many businesses stay for long years due to the positive perception of youth about the founder, who might the great grand-fathers or great grand-mothers who established the business. Buheji (2017b).

Hence, the youth's perception and realisation about their parents' values and beliefs would make them communicate or participate more eagerly in closing the gaps consistently. This found to be highly related to the originality of the messages between the parents' and their children.

\subsection{Measures of the Generation Gaps}

\subsubsection{The Different Generations Gaps}

The majority of each generation experience their own ways of mental and physical maturation, but they also create new aspects of attending school, forming new households, starting families and even creating new demographics.

The generation gap is more noticed today due to the way transitions in different life phases. Today, transitions have become much more complex and are frequently non-linear), compared to earlier generations where the transition sequence often involved a move from education to work, (Furlong et al., 2003).

The maturity of any generation is reflected in its diversity. This generation has more chances for women leading the social change and often could be seen to occupy professional and managerial positions. This drastic culture and generation gaps create issues of community preferences as well as spending. Najafiasl (2015).

Also, this generation would witness more digital divide and income gap, where the $2 \%$ own more than $90 \%$ fortune and where relative poverty would spread even in the middle class. Both $Y$ and $Z$ generation would also witness a clear jump in ages starting from the generation $\mathrm{X}$ and even some of the baby boomers depending on the national healthcare system. Buheji (2018b).

All the latest generation, $\mathrm{Y}, \mathrm{Z}$ and Alpha are expected to develop more prejudicial attitudes towards older people, old age, and the ageing process. Clearly, you can witness this in the family were ignoring the parents, or the grandparents' ideas became a symptom because of the age difference.

\subsubsection{Intergenerational Contract and Equity}

The intergenerational contract is a type of a social norm or community agreement that define the interaction between members of different generations. It is an essential type of socio-economic practice that would help to calibrate many intergenerational issues, including equity, conflict, and mobility.

We need to build this tacit contract in the mindset of the different living generation which would ensure relationships that define the treatment and interactions fairness between the children, the youth, the adults and the seniors and thus would reduce the intergenerational conflict. In order to avoid the conflict situation between teenagers and adults, or a more 
abstract conflict between two generations.

Intergenerational equity focuses on the socio-economic, psychological, and sociological contexts, between the generations. Intergenerational equity occurs across several fields, mainly in both resilience economy and empathetic thinking. (Buheji, 2018a; 2018b; 2018c).

\subsection{Best Practices in Closing Intergeneration Gap}

Buheji (2017) explained in the handbook how to develop a shared understanding of what is happening to youth, in today and across different generations, as a resource and as a spirit and energy that try to utilise, or optimise, or capitalise on, regardless of age. This generation has been psychologically challenged to maintain their spirit while experiencing far less economic certainty than the prior three generations. Buheji (2017a); Schizas (1999).

China is considered to be a reference for its best practices that ensure effective, sustained intergenerational communication. If you closely observe Chinese family businesses, housing, green parks, you will easily notice intergenerational programs that are highly encouraged by all Chinese municipalities. This would reduce the generation gaps that be seen in many developing and merging economies countries.

Since youth by 2020 would represent the majority of the workforce, Microsoft Europe wanted to close the generation gap through reverse mentoring proactively. Reverse mentoring is seen here as an attempt to meet the constant need to stay on the cutting 'digital' edge.

Each youth generation has a positive responsibility to take affirmative steps to prepare the next generation for successful economic participation. Their responsible self-interest should shape Employers' response to the youth employment challenge in ensuring their firms' long-term growth and innovation, and in securing their access to talent for emerging and future economic needs. Businesses and economic entities looking toward long-term success must give appropriate attention to creating and securing future talent resources, and they have their responsibilities in this area alongside and partnership with government, educators, civil society, and young people themselves. Jiří (2016).

With the increase of abuse of youth energy in wars, violence, terrorism and fundamentalism, youth economy comes to give solutions to manage dissipated energy in this generation proactively. Adopting the youth energy management program will help improve youth ability to find better relations and brings them to meet other generations, Buheji (2018b)

\section{Methodology}

In order to create models of generation gap alleviation, an international inspiration economy project (IIEP) started series of different field explorations, in Bahrain, Bosnia, Morocco and India. The longitudinal period of the IIEP started from September 2015 till June, 2019. The case study in this paper lists down two main approaches to be tested for their accumulated effectiveness, based on the synthesis of the literature. The first approach focus on changing the mindset of the different generations involved in the project, but specifically youth. The second approach focuses on the socio-economic engagement between the different types of generations involved in the projects.

The researcher targets test whether the approaches help to alleviate the generation gap and then specify the projects that help to close such a gap. The main target is to come up with a framework that would help to overcome the mindset of the youth and raise their capacity to deal with the 'psychological challenges' that block their effective communication with the different generations, while integrating them with their community's socio-economic conditions.

The methodology of IIEP explores the type of deliberate challenges that would help to build and maintain youth relation with the different generations while pulling them towards managing their socio-economic uncertainties.

Through different generation gap alleviation projects, the researcher focuses on creating intergenerational contract and equity between the different generations using 'learning by interaction'. Since there is a high probability that both generations share the same concern, but not necessarily the same solution. This methodology is exploring possibilities of building common groups that enhance indirect communication model.

Due to the scope and the limitations of the paper, the researcher selected only fourteen projects out of more than 63 projects that targeted elimination of generations gap, or building common language about the different community generations. The ages involved in each project varies depending on the nature of the project, the type of the beneficiaries or partners involved; besides their availability at the time of the project. However, the bandwidth of the age reflects the extent of probability of common grounds that could be achieved through the intergeneration involvement. A framework is then withdrawn based on both approaches proposed. 


\section{Case Study}

The cases of the IIEP targets to improve the availability of life purposefulness of youth to overcome their life challenges while working with different generations. This would improve their employment opportunities, their equality, their quality of life and their learning capacity. Table (1) is part of cases of community socio-economic problem-solving list that were reported by Buheji (2019d) for projects done between 2015 till 2019.

Table 1. Proposed Approaches of Generations Gap Alleviation through selected Socio-Economic Projects

\begin{tabular}{|c|c|c|}
\hline $\begin{array}{l}\text { Type Generation Gap } \\
\text { Alleviation Project }\end{array}$ & Summary of Projects & $\begin{array}{l}\text { Ages Involved in } \\
\text { the Project }\end{array}$ \\
\hline \multicolumn{3}{|l|}{ One - Mindset Approach } \\
\hline $\begin{array}{l}\text { Psychological } \\
\text { Interaction }\end{array}$ & $\begin{array}{l}\text { 1-Raise Inspiration of capacity to manage the anxiety to avoid } \\
\text { reaching the level of chronic anxiety } \\
\text { 2-Reduce the need to treat anxiety with medicines. } \\
\text { 3-Reduce suicide ratio due to early treatment of main } \\
\text { causalities among youth. }\end{array}$ & $13-70$ \\
\hline Business Expertise & $\begin{array}{l}\text { Ensuring the developing capacity in the survival of start-ups } \\
\text { of more than three years on average and development of safe } \\
\text { exits to youth projects. }\end{array}$ & $18-35$ \\
\hline Security \& Safety & $\begin{array}{l}\text { Improving the outcome of creating "Self-Dependent" youth } \\
\text { in the 'Police Youth Summer Camps' which is held for three } \\
\text { weeks. }\end{array}$ & $13-45$ \\
\hline \multicolumn{3}{|c|}{ Two - Socio-Economic Engagement Approach } \\
\hline $\begin{array}{l}\text { Basic Community } \\
\text { Services }\end{array}$ & $\begin{array}{l}\text { 1-Support family continuity and encouragement of Moroccan } \\
\text { Youth into the different streams of organic farming. } \\
\text { 2-Improve measures of Youth Quality of Life through } \\
\text { competition that encourage to increase the number of hours } \\
\text { spent with older generations. }\end{array}$ & $13-80$ \\
\hline $\begin{array}{l}\text { Common } \\
\text { Socio-Economic Issues }\end{array}$ & $\begin{array}{l}\text { 1-Enhance young girls' involvement in Woman village } \\
\text { activities to ensure the sustenance of knowledge transfer. } \\
\text { 2-Integrating youth with both formal sport and traditional } \\
\text { games }\end{array}$ & $13-65$ \\
\hline $\begin{array}{l}\text { Complicated } \\
\text { Socio-Economic Issues }\end{array}$ & $\begin{array}{l}\text { 1-Build youth independence program that counters poverty } \\
\text { through raising the capacity of the farmers for competitive } \\
\text { packaging and distribution. } \\
\text { 2-Build youth trust in the village system as a source of } \\
\text { income }\end{array}$ & $13-60$ \\
\hline $\begin{array}{l}\text { Societal Risk Mitigation } \\
\text { Programs }\end{array}$ & $\begin{array}{l}\text { 1-Mitigation of Migration amongst Bosnian Youth } \\
\text { 2-Optimise the Youth Quality Life through Students Pull } \\
\text { thinking targeted programs } \\
\text { Building Youth Entrepreneurship \& Innovation programs } \\
\text { 3-Enhancing Youth contribution in voluntary work through } \\
\text { rectifying and supporting change in Football Club. }\end{array}$ & $18-70$ \\
\hline
\end{tabular}

\section{Analysis and Discussion}

Generations gaps are related to many casualties, one of which are the internal family relations but also related to both formal and informal culture changes. Literature review shows that there is a need for comparative studies between all the different current approaches that are trying to close the intergenerational gap. The intergenerational gap is becoming more and more a threat to community stability and the loss of many opportunities that can be discovered through the integration of knowledge and expertise between the different generations.

As a result of both approaches followed, the following framework is proposed, as shown in Figure (1). The Figure represents the intergeneration gap alleviation framework and its proposed communication flow. 


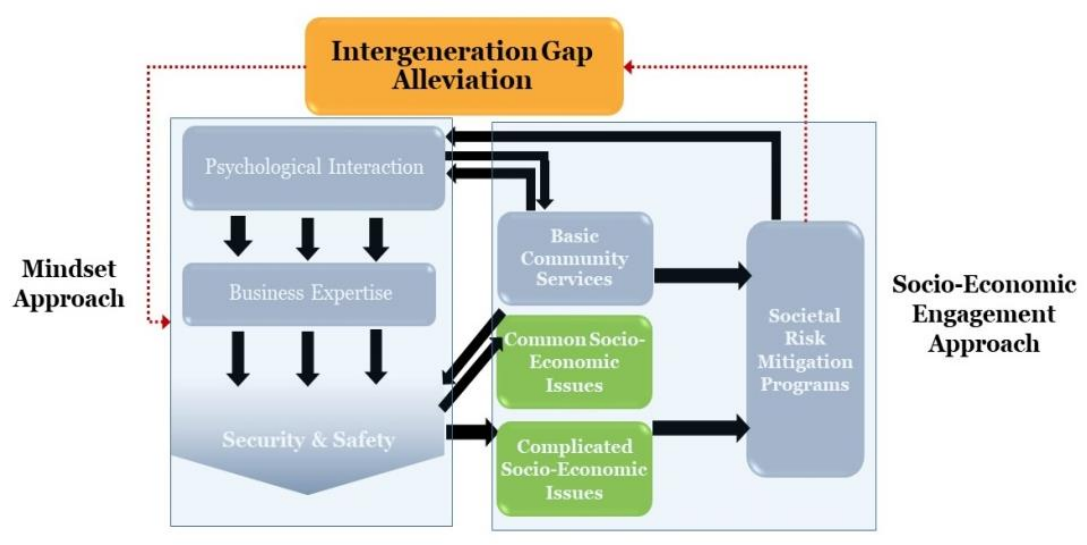

Figure 1. Intergeneration Gap Alleviation Framework

Hence, to alleviate the generation gap, we need to involve youth and even engage them in family or community projects. Therefore, IIEP projects followed two approaches: mindset change and socio-economic projects engagement to close the gap between the youth and the different generations. The case study present socio-economic projects that give possibilities of closing the generation gap by integrating the different generations and especially youth into projects that increase or appreciate the psychological interaction, the business expertise, the security or safety and the girls and women empowerment. The cases of IIEP brings in another attempt of engagement of youth through the poverty elimination projects, the societal change programs, the organic farming projects, the bringing low privileged community children to formal education. Such generation gap alleviation projects

Part of the approaches of compensating the inadequate social assets that became weaker and weaker due to technological advancement brings in more learning through exploring the different generation. This would help to develop flexible generation mindest that make each appreciate others perspective.

\section{Conclusion}

Despite all the type of future foresighted complex socio-economic problems, the challenge of connecting the different generation would stay the most prominent problem that we need to overcome over time and between the different generations. This connection cannot be taught or specified by design; it comes only to be achieved through doing. Over time the world lost the ability and the capability to make generations connections and this even increased more with the fast-changing world.

Engaging the different generations, in the common good is becoming of the primary means towards generations engagement. Therefore, this research sets a model for bridging the generation gaps through socio-economic projects.

The limitation of this paper is that it did not go through the levels of generation gaps and its impact as a type of disputes and the frequency of arguments. Besides, and due to the limitations of the scope of this paper, the outcome of two approaches followed is not covered in this paper. The researcher also avoided identifying the type of current intergeneration gaps that have been eliminated and which would be reported in another future paper.

In order to generalise the framework proposed, mastering the knowledge of the different generations gone through both approaches, the mindset and the socio-economic projects engagement need to be studied in the future. The researcher recommends to setup a team of mentors that would ensure that each targeted youth goes through the framework. This presumably would generate a new experienced generation that could be more engaged in complex socio-economic issues.

Finally, this study and its framework resemble the metaphor of the 'escape-room game' which enhances the communication between the different teams (players) and make them share their wisdom and 'know-how'. Such an environment provides an environment that would allow the free exchange of ideas between the different generations. The paper opens the road for more alternative approaches in the future that could bring more common issues and trigger the mindset of youth and their community generations towards working on common goals and from different angles and perspectives.

\section{Reference}

Buheji, M. (2019). Youth Unemployment Mitigation Labs - An Empathetic Approach for Complex Socio-Economic Problem. American Journal of Economics, 9(3), 93-105.

Buheji, M. (2018a). Foreword - 'Youth Role in Transforming Change towards a better World'. International Journal of 
Youth Economy, 2(2), I-II.

Buheji, M. (2018b). Handbook of Youth Economy. AuthorHouse, UK.

Buheji, M. (2018c). Understanding the Power of Resilience Economy: An Inter-Disciplinary Perspective to Change the World Attitude to Socio-Economic Crisis, AuthorHouse, UK.

Buheji, M. (2018d). Re-Inventing Our Lives, A Handbook for Socio-Economic "Problem-Solving”. AuthorHouse, UK.

Buheji, M (2017a). Forward-Youth Economy and Utilisation of Lost Opportunities. International Journal of Youth Economy, 1(2), 1-2.

Buheji, M (2017b). Inspiring GCC Family Business towards Lean Governance: A Comparative Study with Japanese FB'S. $V(7), 75-88$.

Dilthey, W (1923). Introduction to the Human Sciences, an attempt to lay the foundation of the study of Society and History.

Furlong, A. (2016). The changing landscape of youth and young adulthood. In: Furlong, A. (Eds.), Handbook of Youth and Young Adulthood [2nd ed.]. Series: Routledge international handbooks. Routledge: Abingdon, Oxon; New York, NY, pp. 3-11.

Govitvatana, W. (2001). Generation Gap in the Workplace between Baby Boomers and Generation X. Master Thesis. The Graduate College University of Wisconsin-Stout, Publication Manual of the American Psychological Association. Retrieved from https://core.ac.uk/download/pdf/5065856.pdf

Jiří, B. (2016). The Employees of Baby Boomers Generation, Generation X, Generation Y and Generation Z in Selected Czech Corporations as Conceivers of Development and Competitiveness in their Corporation. Journal of Competitiveness, 8(4), 105-123, December. Retrieved from https://www.cjournal.cz/files/236.pdf

Mannheim, K. (1952). The problem of Generations, Essays. In Paul Kecskemeti (Eds.) Routledge, pp. 276-322. Retrieved from http://marcuse.faculty.history.ucsb.edu/classes/201/articles/27MannheimGenerations.pdf

Schizas, C. (1999) Capitalizing on a generation gap. Management Review, 88(6), 62.

Woodman, D., \& Wyn, J. (2015). Youth and Generation: Rethinking Change and Inequality in the Lives of Young People. Sage, London.

Najafiasl, Z. (2015) Intergenerational Gap: An Emerging Phenomenon in Iran. International Journal of Social Sciences (IJSS), 5(1), 59.

\section{Copyrights}

Copyright for this article is retained by the author(s), with first publication rights granted to the journal.

This is an open-access article distributed under the terms and conditions of the Creative Commons Attribution license (http://creativecommons.org/licenses/by/4.0/). 